Article

\title{
Predictors of Ambient Intelligence: An Empirical Study in Enterprises in Slovakia
}

\author{
Vladimír Bolek *(i) and Anita Romanová $\mathbb{B}$ \\ Department of Information Management, Faculty of Business Management, University of Economics in \\ Bratislava, Dolnozemska cesta 1/b, 85235 Bratislava, Slovakia; anita.romanova@euba.sk \\ * Correspondence: vladimir.bolek@euba.sk
}

Received: 17 August 2020; Accepted: 9 October 2020; Published: 11 October 2020

\begin{abstract}
Integration of innovative pervasive technologies into the surrounding environment creates ambient intelligence which has become the subject of several scientific and academic considerations. In particular, the pervasive technology is based on Internet of Things (IoT) and Industrial Internet of Things (IIoT). Ambient intelligence may be viewed from several perspectives: a technological, multi-aspect and visionary point of view. Several predictors influence the level of ambient intelligence. The aim is to identify significant predictors influencing ambient intelligence and simultaneously determine their impact on the achieved level of ambient intelligence of the company. In the research methodology, we acknowledge the research presumptions, the research question and research hypotheses, the measurement instrument, obtained data and methods used in accordance with the research model. The scientific article presents the results of an empirical study conducted on 206 enterprises, focusing on the examining of the influence of selected predictors on the level of ambient intelligence in enterprises in the Slovak Republic. It examines not only the influence of selected predictors on the level of ambient intelligence, but also their mutual interaction. We found that these activities even build ambient intelligence on their own, although in interaction with each other, their effect on the level of ambient intelligence begins to fade. Therefore, it is necessary to opt for their combination appropriately. Finally, we present the limits of the research and suggestions on further directions of research in this field.
\end{abstract}

Keywords: ambient intelligence; pervasive technology; data; virtualization; digitization; Internet of Things

\section{Introduction}

Innovative pervasive technology and the internet network, which have caused the industrial revolution in society, are becoming hyper-aware systems, representing highly flexible technologies, following clear algorithms, responding not only to human commands but also to their own perception and direction. Literature shows that in connection to the integration of innovative technologies in business processes, we encounter the concepts of data collection and analysis, new ubiquitous technologies, sophisticated sensors, robotics, cloud computing, Internet of Things (IoT), digital manufacturing, autonomy, interoperability of systems, digitization, virtualization, artificial intelligence, augmented intelligence, surrounding intelligence.

Implementation of such technologies in business processes creates a new environment called ambient intelligence of a company. Ambient intelligence is a concept developed by The EU Information Society Technologies Programme Advisory Group-ISTAG [1,2]. Ambient intelligence is the founding concept of normative visions for information technologies in the European Union. It provides a general framework for the future of the European information society and its long-term vision. Ambient 
intelligence services in IoT environments is an emerging research area that can change the way that technology and services are perceived by the users [3].

In this paper, we examine the influence of selected predictors (data significance, data analysis degree, digitization level, virtualization level, level of augmented reality implementation, management attitude) on the level of ambient intelligence in enterprises in the Slovak Republic. The remainder of the paper is structed in line with the DSR publication scheme proposed by Gregor \& Havner [4]. In Theoretical Background, we analyse and compare theoretical starting points. We divide the analysed and compared theoretical background into three groups: technologically, multi-aspect and visionary perceived definitions. We identify the research problem and six significant variables which we refer to as predictors of building the enterprise's ambient intelligence. In Research Methodology, we acknowledge the research presumptions, the research question and research hypotheses, the measurement instrument, obtained data and methods used in accordance with the research model. In the work's results section, we test six hypotheses based on the established assumption and the research question. We verify the research hypotheses on the research sample $(n=206)$, which comprises companies in the Slovak Republic. The aim is to identify significant predictors influencing ambient intelligence and simultaneously determine their impact on the achieved level of ambient intelligence of the company. The Discussion section provides a discussion of the paper's contributions, where we discuss significant findings on the impact of predictors on the level of ambient intelligence in enterprises, we compare these findings with the conclusions of studies by other authors and we point out the limitations of the research. In the Conclusions section, we summarize the obtained results and introduce future direction of the research.

\section{Theoretical Background}

Ambient intelligence represents a new paradigm. The paradigm is, at any time and anywhere, becoming a new challenge for the conception of the next generation of information and communication technologies, which are characterized by their ubiquity. Trends in IT are focusing on new innovative technologies, new infrastructure of information system designs as ubiquitous (pervasive), i.e., systems that are accessible from anywhere, at any time and with almost any electronic device. However, the use of such ubiquitous access to information systems requires new concepts, models, methodologies and assisting technologies that can fully exploit its potential. In this context, mobility introduces new accessibility scenarios and increases requirements in enterprises providing IT services and products.

Ambient intelligence consists of information systems and technologies that have intelligent, highly analytical capabilities while individual technologies are allowing targeted and flexible support of a complex ambient system. The ambient system is configured by using various components which are integrated into the user's environment. Users may personalize and customize the system to suit their personal needs. The adaptive components of the system may vary depending on individual requirements. An important element of the system are components which are not often directly visible, but they provide support to the surrounding environment, so they can be considered ubiquitous (pervasive).

Based on a detailed analysis and comparison of theoretical background, we classify the authors' definitions of ambient intelligence into three groups (technologically-oriented definitions, multi aspect-oriented definitions, visionary-oriented definitions), and we put them in chronological order so that the development in this area may be clearer and we are able to identify fundamental elements that the authors primarily focus on when defining ambient intelligence. We named the categories according to the essence of the definition of ambient intelligence (technologically oriented, multi aspect-oriented, visionary-oriented).

\subsection{Technologically Oriented Definitions}

Technologically oriented definitions define ambient intelligence from the point of view of technologies, considering technological aspect, often listing specific technologies which create ambient 
technology and point out the benefits for the society. Ambient technology brings a special view on ongoing research related to technical areas such as ubiquitous and proactive work with information and communication technologies [5].

Ambient intelligence from a technological point of view also integrates information technologies and the human factor. The emergence of ambient intelligence [6] was inspired by the fact that current technological development enables integration of information and communication technologies into the surrounding environment. In addition, there is currently a growing desire to strengthen the role of information and communication technologies in the surrounding environment and not only to increase productivity. Ambient technology can also be defined as the convergence of three key technologies: computer, communication and intelligent user interface [7]. In the context of technological perception, Shadbolt [8] complements the initial definition of ISTAG with a broader understanding of mobility. Users of mobile technologies are able to use them to communicate and transmit information to relevant systems. Furthermore, their location and other data in the surrounding environment are monitored and that makes it possible to obtain new contextual information. Thus, ambient intelligence systems can improve user activity and at the same time devices can perform certain specific tasks based on their delegation $[9,10]$.

We agree that ambient intelligence responds to technological challenges. It aims to provide the most consistent contextual information and transformation of data into knowledge [11-13]. Ubiquitous connectivity [14] of sensors in a noisy industrial environment presents a challenge. The sensor data need to be periodically collected and securely delivered to cloud storage or smart spaces for processing. It is an evolving technology that is increasingly becoming an everyday part of life, sensitive and responsive to our presence [11].

The presence of the human factor in combination with technology-oriented definitions is identified in several studies. Vasilakos and Pedrycz [15] state that in the environment of ambient intelligence people are surrounded by networks, built into intelligent devices which are able to assess the current state and are able to adapt to the needs of users. Ambient intelligence can be considered to be a digital environment that supports people in their daily lives in a non-intrusive way [16].

The most significant technological aspects are emphasized by Augusto and McCullagh [17] who refer to ambient intelligence as the integration of sensors, information technologies, network connection, ubiquitous computing power and human interaction. Ambient intelligence deals with a new world of ubiquitous computing devices, where the physical environment integrates the virtual reality and its users [18].

The paradigm of ambient intelligence is based on previous visions of mobile devices and smart devices. The importance of ambient intelligence is in the need for extensive implementation of technology so that it becomes an integral part of daily used objects in the surrounding environment [6].

There has been a significant chronological development observed in computational paradigms. These are transparent, easily accessible and intelligent technologies. There is meaningful progress in technology, which shows the signs of ubiquitous computing power. It is created according to the requirements of people in interactive environment and it responds to their various needs [19-21].

The Internet of Things (IoT) plays an important role. The authors Gurtov, Liyanage and Korzun [14] remind: "The term Internet of Things (IoT) was initially proposed to refer to uniquely identifiable interoperable connected objects with radio-frequency identification (RFID) technology. Now the most common view of IoT refers to a giant dynamic global network infrastructure for the ubiquitous connection of numerous physical objects (e.g., everyday things equipped with RFIDs, various sensors and actuators, embedded and mobile electronic devices, low capacity and powerful computers) that rely on advanced communication and information processing technologies."

Other authors [22-25] state that IoT aims at the fusion of real (physical) and virtual (information) worlds, and the IoT concept evolves to service-oriented information interconnection and convergence.

Current definitions of ambient intelligence refer to it as a set of technologies that intercommunicate autonomously in a value chain. Computer systems monitor physical processes, create a virtual copy of 
physical worlds and make decentralised decisions based on self-intelligence mechanism [26]. "Novel technologies should not primarily increase functional complexity, but they should also contribute to the development of easy to use and simple to experience products and services, that make sense in the first place" [6].

Technologically oriented definitions provide a clear overview of what the technologies that form the substance of ambient intelligence are and what their goal is. The authors often list technologies and emphasize their intercommunication and interoperability. They integrate these technologies and systems into the surrounding environment in a way that the user is not aware of it or only just perceives their presence. At the same time, we identify with the statement of Kaptein [27] who states a great part of characteristics and definitions oriented towards the area of ambient technology, but does not focus on the importance of data, development and assessment of the data collecting methods, processing or data estimation and the extent of their analysis. This measure is often omitted in definitions and its importance is forgotten. The definitions focus mainly on the development and assessment of new applications, user involvement and social responsibility of such applications. Machine intelligence is considered a matter of course, which is a useful foundation, it allows this area to study effectively and to reason future emerging technologies and to integrate the users into the application proposals before they are realized technically. From the point of view of Kaptein [27], however, it is appropriate to explicitly assess the impact of the importance of data analysis, the extent of data analysis for the enterprise, because they have a significant impact on building the environment of ambient intelligence.

\subsection{Multi Aspect-Oriented Definitions}

Ambient intelligence takes into account also different aspects, i.e., the humane, socio-economic and social aspect. Several authors do not exactly refer to technologies that make up ambient intelligence, but also recall other aspects, which complete its essence.

Ambient intelligence responds to the technological challenge. Progress in the field of artificial intelligence and environmental intelligence is governed by rules and laws that are similar to those in the field of information and communication technologies. Many of these principles, such as Moore's law, are exponential. Despite some indications that progress is slowing, it is likely that artificial intelligence and ambient intelligence will continue to grow rapidly in the near future.

A holistic approach in the definition of ambient intelligence is key. It is focused on integration of its users for the purpose of its development. Ambient intelligence must be driven by humanistic issues that are not technologically determined and must be controllable by ordinary people.

We observe the fact that ambient intelligence has become a multidisciplinary topic of interest in many research areas, where its positive impact on society can be identified. It is a new vision and a new concept. It gathers several functions relating to the integration of information technologies into the environment in cooperation with the user. The whole system must respond intelligently to the requirements of its users. Intelligence relates to the ability to teach and apply the knowledge in new situations. The aim of ambient intelligence [17] is to improve the way people communicate with each other. The ultimate goal in this area is to create places where we live and work. Smart Homes is one of the examples of these systems, but, in addition, this idea may be used in hospitals, on public transportation, factories and other environments.

In the definition of ambient intelligence, Charitos [28] points to the potential non-verbal and spatial communication interfaces for design procedures of ambient intelligence. The design of ambient intelligence is focused on the human factor that would exceed the scope of "intelligent" technology-oriented ubiquitous devices and equipment. This approach is characterized by the retention of the human factor as a control mechanism. Regarding the combination of the human factor and "intelligent" devices and spaces, Streitz [29] argues that "intelligent" devices and spaces make people smarter.

Ambient intelligence, among other things, represents moving the perception of information technologies and information systems forward and improving the interaction with the human factor in 
order to support security and improve the quality of life, economic results of enterprises and their productivity $[6,17]$.

Streitz $[29,30]$ speaks about a "SmartEverything" paradigm, the resulting proposal for compromises for privacy and human control and their application in smart cities. Definitions of ambient intelligence of this author are based on a combination of the Internet of Things (IoT) and artificial intelligence. Technological perception disappears from the definitions. All elements of life become intelligent whether it is software, hardware, specific platforms or services. Smart or intelligent concepts require critical reflection and alternative perspectives, especially in combination with increasing of automation and autonomous systems. An alternative is an approach which exceeds the scope of "intelligent" environments towards the humane and social environments of ambient intelligence. It has roots in the initial vision of ambient intelligence and requires a redefinition of "all intelligent" paradigms [29]. Ambient intelligence must also accept humane and social environment, its rules and frameworks. It cannot be based purely on technological perception. Now is the right time to promote this humane and social perspective and adapt it to the new constellations. This alternative view of Streitz [29] is based on compromises between the technical perception and the humane and social view of ambient intelligence.

Multi aspect-oriented definitions complement technologies with humane, economic and social perspectives. They emphasise the communication of technologies and their users, point to the change of life nowadays, the creation of new ecosystems taking into consideration the established rules and they point out the need to create new rules and frameworks.

\subsection{Visionary-Oriented Definitions}

The third group of authors characterize ambient intelligence as a potential future, the definitions provide a visionary view of this paradigm; the authors point to the environment that changes society. Ambient intelligence is a vision of the future of everyday life. It contains the assumption that intelligent technology should enter our environment so it brings a simple and amusing life to people [31]. Ambient intelligence represents a potential environment, in which we shall be surrounded by intelligent technologies that recognize the presence of people and shall respond to them [7]. The authors Fabian et al. [32] perceive ambient intelligence in a visionary way. They theorize that ambient intelligence understood from the point of view of information technologies, mobility and communication is accepted by society. There is a need to emphasize its visionary nature and look to the future. This view is rather rarely encountered in literature.

In the case of visionary-oriented definitions, it can be observed that the center of attention is no longer in the hardware, neither in the computer, nor in the network. Intelligence must be provided in everyday environment. We are aware of the pressure towards intelligent homes, intelligent vehicles, intelligent transportation, intelligent manufacturing systems and even intelligent cities. This is the reason why the concept of ambient intelligence is so important nowadays [33].

The visionary perception of ambient intelligence [6] originates in previous visions of mobile and smart devices. The meaning of ambient is in the need for extensive implementation of technology so that it becomes an integral part of everyday objects in the surrounding environment. The meaning of intelligence reflects the digital environment showing specific forms of social interaction, integration of information technologies, information systems. Ambient intelligence will create a digital environment which is sensitive, adaptable and responsive to human presence [16,34]. The philosophy of ambient intelligence offers a concept of environment which will be sensitive and responsive to human presence. The idea is based on advanced results of interdisciplinary research. The development of ambient intelligence applications is a complex task and all their properties and functioning properties are difficult to predefine or predict due to various emerging or synergistic effects [35].

This group of visionary-oriented definitions predicts the direction of ambient intelligence. The authors create a vision of a digital ecosystem that responds intelligently and autonomously to user requirements. 


\subsection{Theoretical Findings}

Based on the study of the literature, we state that the authors use different definitions of the term ambient intelligence. There is no clear specification of ambient intelligence. In the definitions of ambient intelligence, the authors mainly focus on ubiquitous power [14,36,37], communication [38,39], mobility [40], intelligence [7,41]. The attention in the area of ambient intelligence focuses also on the integration of the human factor $[19,42]$ and the interaction of innovative pervasive technology. Based on the study of theoretical background, we defined the most significant features of ambient intelligence found in the definitions of several authors (Table 1).

By creating a synthesizing table (Table 1) containing the main features of ambient intelligence, which are covered by the definitions of the authors, we identified that technologically oriented definitions occurred earlier than 2005. In the period 2005-2007, the authors begin to work with the notions of perception, device sensitivity, interoperability, adaptability and they point out their pervasiveness. The definitions defined later than 2007 appear to be a kind of channel to technologically and visionary-oriented definitions with the addition of the dimension of intelligence. Intelligence is defined as the ability to respond to user requirements, often reminding that the ambient system does not require constant settings or parameterization as it is able to learn on its own.

Studying the literature sources and research studies, we found that the authors do not address the issue of ambient intelligence from the point of view of business management and they do not examine the interaction of individual effects on achieving it. During the study of the issue, we did not find in the available sources any studies that would provide conclusions from the surveys applied to companies without size or industry limitations. It mainly regarded theoretical studies, confrontation of conceptual apparatus, scenarios, views, recommendations, challenges of the authorities of the Member States of the European Union, national and international concepts. The studies provided mostly visionary views, application-oriented studies focused on ambient intelligence in one specific area (healthcare system, construction industry, etc.) The identification of the research gap was one the factors influencing the choice of this topic for our research focus.

Based on the analysis of theoretical background, systematization and generalisation, we defined the definition of ambient intelligence. Ambient intelligence represents a multidisciplinary approach, integrating innovative pervasive technologies and systems that form an ecosystem, which, based on collected, transformed, analysed and evaluated data, respond to user requirements intelligently.

Ambient intelligence represents a multidisciplinary approach which focuses on the integration of innovative pervasive technologies that support user activities through specific environmental services that are provided with minimal user interference. Essentially, the system of ambient intelligence should be aware of a person's presence, understand the person's needs and be able to adapt to them. Ambient intelligence brings new findings about the environment for software development and implementation, where there are large quantities of various devices and sensors that need to be integrated, creating a programmable and auto-configurable infrastructure of information systems. The centre of attention is no longer in hardware, neither in computer, nor network, but in providing intelligence in an everyday environment. In other studies in the literature, we identified significant predictors building ambient intelligence. Other authors investigated these predictors only partially. We do not only examine the influence of these predictors building ambient intelligence in the enterprise, but also their interaction, so our research work develops the current state of knowledge in this area. 
Table 1. The main features of ambient intelligence.

\begin{tabular}{|c|c|c|c|c|c|c|c|c|}
\hline & Technologies & Virtuality & Sensitivity & Perception & Adaptability & Reality & Pervasiveness & Intelligence \\
\hline (ISTAG, 1999; ISTAG, 2003) & $x$ & - & - & - & - & - & - & - \\
\hline (I.A. Group, 2001; Ducatel, 2001) & - & - & $X$ & $X$ & - & $X$ & $X$ & - \\
\hline (Aarts et al., 2001) & $x$ & - & - & - & - & - & - & - \\
\hline (Ducatel, 2001) & $X$ & - & - & - & - & - & - & - \\
\hline (Ahola, 2001) & $X$ & - & - & - & - & - & - & - \\
\hline (I.A. Group, 2001) & $X$ & - & - & $x$ & $X$ & - & $X$ & $X$ \\
\hline (Rech and Althoff, 2004) & - & - & - & - & - & $x$ & - & $x$ \\
\hline (Remagnino et al., 2005; Weber et al., 2005) & $x$ & - & - & - & $x$ & - & - & $x$ \\
\hline (Aarts \& Encarnaçao, 2006) & - & - & $x$ & $x$ & - & - & - & - \\
\hline (Maeda \& Minami, 2006) & - & - & - & - & - & - & $x$ & $x$ \\
\hline (Crutzen, 2006) & - & - & - & $x$ & - & $x$ & $X$ & - \\
\hline (Vasilakos \& Pedrycz, 2006) & - & - & $X$ & - & $X$ & $X$ & $X$ & $X$ \\
\hline (Phillips Research, 2007) & - & - & $X$ & $x$ & $X$ & - & - & - \\
\hline (Phillips Research, 2007) & - & - & - & - & - & $X$ & $X$ & - \\
\hline (Augusto and McCullagh, 2007) & - & - & - & - & - & - & - & - \\
\hline (Ramos, 2007) & $x$ & - & - & - & - & - & - & - \\
\hline (Ramos, Augusto \& Shapiro, 2008) & $x$ & $x$ & - & - & $x$ & - & $x$ & - \\
\hline $\begin{array}{c}\text { (Aarts et al., 2001; Aarts and Encarnação, 2006; } \\
\text { Cook et al., 2009) }\end{array}$ & $x$ & - & - & - & - & $X$ & - & - \\
\hline (Veronica et al., 2009) & $x$ & - & - & - & - & - & - & - \\
\hline (Aarts and De Ruyter, 2009) & $x$ & - & - & - & - & - & - & - \\
\hline $\begin{array}{c}\text { (Kleinberger et al., 2007; Van Hoof, 2011; } \\
\text { Bravo et al., 2014; Korzun, Balandina and } \\
\text { Kashevnik, 2019) }\end{array}$ & $X$ & - & - & - & - & - & $X$ & $X$ \\
\hline (Smit et al., 2016) & $x$ & $x$ & - & - & - & - & - & $x$ \\
\hline (Bureš et al., 2016) & - & - & $X$ & $X$ & $X$ & - & $x$ & $x$ \\
\hline
\end{tabular}




\section{Materials and Methods}

In accordance with the findings in the theoretical background and the identification of the research gap, we set a research assumption, a research question and, in order to provide an exact answer, we formulated research hypotheses. The solution of the research problem is supported by the use of scientific methods in connection with the proposed research model (Figure 1).

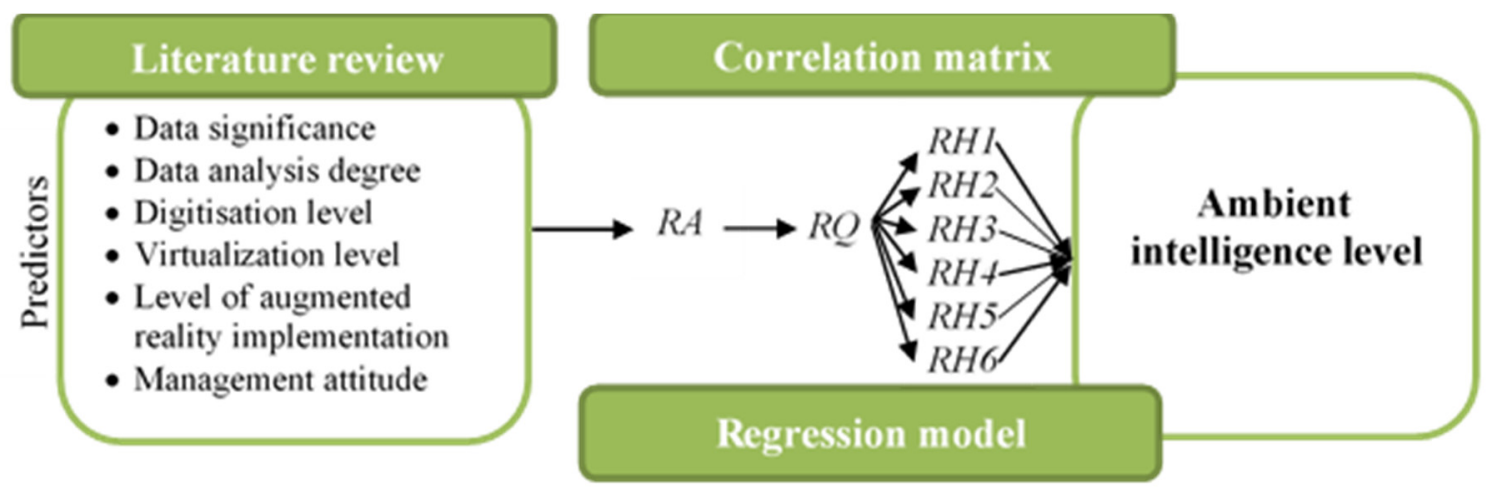

Figure 1. Research model. Notes: RA—research assumption, RQ-research question, RH—research hypothesis. Source: own processing.

\subsection{Research Design}

Based on the findings, we state that some authors define the definitions of ambient intelligence in studies too technically, they characterize individual technologies [14,17], pointing to predictors such as significance of data and degree of analysis [14,27], level of digitization [12], level of virtualization $[18,26]$ and level of augmented reality implementation [19-21]. In several analyzed theoretical approaches $[5,6,18,28,42]$ a significant influence of the human factor can also be identified in innovative pervasive technologies.

\subsection{Research Assumption, Question and Hypotheses}

$R A$ : In determining the research question, we assume that the activities resulting from the integration of innovative pervasive technologies into business processes and the attitude, the relationship of business management to these technologies has a significant impact on the level of ambient intelligence of the enterprise.

RQ: How do selected activities (data analysis, digitization, virtualization of business processes, implementation of augmented reality and attitude, the relationship of business management to data (significance of data), to innovative pervasive technologies) affect the achieved level of ambient intelligence of the enterprise?

RH1: $\mathrm{H}_{0}$ : The significance of data has statistically no significant effect measured by linear regression on the achieved level of ambient intelligence of the enterprise. $\mathrm{H}_{1}$ : The significance of data has a statistically significant effect measured by linear regression on the achieved level of ambient intelligence of the enterprise.

RH2: $\mathrm{H}_{0}$ : The data analysis rate has statistically no significant effect measured by linear regression on the achieved level of ambient intelligence of the enterprise. $\mathrm{H}_{1}$ : The data analysis rate has a statistically significant effect measured by linear regression on the achieved level of ambient intelligence of the enterprise.

RH3: $\mathrm{H}_{0}$ : The level of digitization of business processes has statistically no significant effect measured by linear regression on achieved level of ambient intelligence of the enterprise. $\mathrm{H}_{1}$ : The level of digitization of business processes has a statistically significant effect measured by linear regression on the achieved level of ambient intelligence of the enterprise. 
RH4: $\mathrm{H}_{0}$ : The level of virtualization of business processes has statistically no significant effect measured by linear regression on the achieved level of ambient intelligence of the enterprise. $\mathrm{H}_{1}$ : The level of virtualization of business processes has a statistically significant effect measured by linear regression on the achieved level of ambient intelligence of the enterprise.

RH5: $\mathrm{H}_{0}$ : The level of implementation of augmented reality elements into business processes has statistically no significant effect measured by linear regression on the achieved level of ambient intelligence of the enterprise. $\mathrm{H}_{1}$ : The level of implementation of augmented reality elements into business processes has a statistically significant effect measured by linear regression on the achieved level of ambient intelligence of the enterprise.

RH6: $\mathrm{H}_{0}$ : The attitude of management to integration of innovative pervasive technologies has statistically no significant effect measured by linear regression on the achieved level of ambient intelligence of the enterprise. $\mathrm{H}_{1}$ : The attitude of management to integration of innovative pervasive technologies has a statistically significant effect measured by linear regression on the achieved level of ambient intelligence of the enterprise.

\subsection{Measuring Instrument}

A questionnaire was selected as a measuring instrument in the research. Its concept emerges from a detailed analysis of literature sources, familiarity with the current situation in the area of business management, information and communication technologies and case studies, semi-structured and structured interviews with enterprises cooperating in scientific research activities of a faculty and a university department, mentors in the area of building ambient intelligence in enterprises.

We state that the measuring instrument (the questionnaire) thus had sufficient constructive validity. The measuring construct empirically shows such relationships with other variables as assumed by the theory. Individual questions and variables were formulated based on induction, deduction and to a certain degree abstraction. The questionnaire (conditions of validity and reliability met) contained open and closed questions, which were measured by using nominal, ordinal and interval variables. The Likert scale from 0 -insignificant impact up to 6-really significant impact was applied. We also used secondary statistical data to reconcile the conclusions we formulated. After obtaining the data, we measured the internal consistency of the questionnaire.

\subsection{Data Collection Methods of Analysis}

The data of the current state of ambient intelligence in enterprises in the Slovak Republic were obtained through questionnaire research conducted by a random selection in the period 09/2018-03/2019 in enterprises in the Slovak Republic, which use ambient intelligence technologies.

The object of the research were enterprises in the Slovak Republic that use ambient intelligence technologies. There were 206 relevant respondents (managers of the enterprises) whose responses were included in the analysis. The representativeness of the sample was ensured by a regional balance, while there was a sample from all Slovak regions. The sample structure (Table 2) according to sectors approximates the distribution of enterprises in the national economy (statistical classification of economic activities-SK NACE). 
Table 2. Structure of the research sample according to industrial sectors.

\begin{tabular}{cc}
\hline Sector & Percentage of Respondents (\%) \\
\hline A Agriculture, forestry and fishing & $5.34 \%$ \\
C Industrial production & $24.27 \%$ \\
D Electricity, gas, steam and air conditioning supply & $0.49 \%$ \\
F Construction & $0.49 \%$ \\
E Water supply; sewerage, waste management and remediation activities & $9.71 \%$ \\
G Wholesale and retail trade; repair of motor vehicles and motorcykles & $12.14 \%$ \\
I Accomodation and food service activities & $5.34 \%$ \\
J Information and communication & $6.31 \%$ \\
K Financial and insurance activities & $8.25 \%$ \\
L Real estate activities & $0.49 \%$ \\
M Professional, scientific and technical activities & $3.88 \%$ \\
N Administrative and support services & $3.40 \%$ \\
P Public administration and defence; compulsory social security & $0.97 \%$ \\
P Education & $3.40 \%$ \\
Q Human health and social work activities & $2.43 \%$ \\
R Art, entertainment and recreation & $0.49 \%$ \\
S Other activities & $12.62 \%$ \\
\hline Total sum & $100.00 \%$ \\
\hline
\end{tabular}

The most represented were enterprises from industrial production, $24 \%$, other activities, $13 \%$ and wholesale and retail, $12 \%$. Enterprises were segmented also according to production/nonproduction activities. The research sample of enterprises segmented by activities consisted of $40 \%$ production and $60 \%$ nonproduction enterprises.

We segmented the enterprises according to size (Table 3) based on recommendation of the European Commission 2003/361/EC, based on number of employees (micro 1-9, small 10-49, medium-sized 50-249, large enterprises $>=250$ ). Within the research sample, the most represented were large enterprises at $28.65 \%$ and medium-sized enterprises at $24.76 \%$.

Table 3. Structure of the research sample according to size.

\begin{tabular}{cc}
\hline Business Size & Number \\
\hline Micro & $17.48 \%$ \\
Small & $19.42 \%$ \\
Medium-sized & $24.76 \%$ \\
Large & $38.35 \%$ \\
Total sum & $100.00 \%$ \\
\hline Source: own processing.
\end{tabular}

We subjected the data obtained by the questionnaire survey to a detailed statistical analysis. We examined the structure of the data file, relationships and the strength of relationships between variables. We predicted the strength of dependency and examined and quantified the functional and casual relationship between the variables using linear regression analysis.

We measured the constructive, concurrent and predictive validity of a research tool. We can prove constructive validity by building the enterprise's ambient intelligence with the predictors we had identified based on a detailed analysis of other studies and theoretical background. At present, we cannot find many studies clearly demonstrating this validity. Other authors examined only partial predictors of ambient intelligence. As far as we know, this is the first empirical study that examines the relationship of individual parts to ambient intelligence and their interaction. Predictive validity is assessed by the behaviour in enterprises. The enterprises behaved as they expressed their attitude to individual predictors and opinions in the questionnaire. The values were not only significant, but their behaviour is also in line with our findings. We can consider this article as the first attempt to define 
these constructs and our empirical data confirm validity of the research tool, which was previously determined only by theoretical assumptions.

The exploratory factor analysis, specifically the principal axis factoring methods with Varimax rotation, were chosen to analyze the internal structure of the questionnaire. The analysis identified 5 factors (latent variables) whose eigenvalue was higher than 1 . The first factor is the strongest and has an eigenvalue of 6.056 and explains up $30.275 \%$ of the variance. Other factors have a smaller eigenvalue: the second eigenvalue factor 1.912 explains $9.562 \%$ of the variance, the third eigenvalue factor 1.521 explains $7.605 \%$ of the variance, the fourth eigenvalue factor 1.273 explains $6.366 \%$ of the variance. The last factor whose eigenvalue was higher than 1 is eigenvalue 1.129 explains $5.646 \%$ of the variance. These 5 factors explain cumulatively $59.458 \%$ variability. All questions loading the first factor are in a positive relationship. By exploratory factor analysis, we found that these questions used in the research all positively load the strongest factor, which we assume is the level of ambient intelligence. Based on the Component Matrix, we identified five factors. The first strongest is ambient intelligence, the factor load of all questions ranged from 0.170 to 0.727 . We called the second factor data analysis. The variables from this factor also positively saturate the first factor-ambient intelligence, but they also form the second independent separate factor. We found the same pattern while we were identifying a separate factor and at the same time questions from it were in a positive relationship to ambient intelligence for the third (digitization), fourth (virtualization) and fifth factor (management attitude). Based on these results, we empirically confirmed for the first time the theoretical construct of ambient intelligence, which is a separate factor and at the same time is formed by digitization, virtualization and a managerial attitude. Based on these results, we conclude that our empirical findings are consistent with the theoretical assumptions described in the theoretical part of the paper.

We used an extensive set of mathematical and statistical methods to assess the data obtained by the questionnaire survey. We measured the accuracy and reliability of the research instrument through reliability-Cronbach's alpha. Traditionally, the value based on a Cronbach's alpha rating of 0.7 to 0.8 is considered a sufficiently reliable scale of the research tool. The reliability of the scale of factors influencing constructing ambient intelligence in a company is $\alpha=0.830$. The reliability of individual questions ranged from $\alpha=0.810$ to $\alpha=0.840$.

From the analysis of the reliability of the research instrument, we state that the scales were designed at a satisfactory level and the results of the statistical analysis of the questionnaire survey are sufficiently reliable and well-interpretable.

The process of identification of predictors influencing the level of ambient intelligence of an enterprise consists of several phases: analysis of the theoretical background, examination of the dependence between the variables (factors) influencing the building of the ambient intelligence of the enterprise through correlation analysis. The indication of a particular possibility on the achieved level of ambient intelligence of an enterprise, via individual predictors of building ambient intelligence, is measured by means of Kendall's Tau-C and Spearman's rho. In the next phase, we examined the functional and casual relationship between the variables and using linear regression analysis, we quantified it exactly. The model is constructed in a way that the statistical significance of individual variables is maintained, but also the whole model is maintained at the level of significance $p=0.05$. In individual models we monitor the significance of the model, individual predictors, the variance of the model measured by the indicator $R^{2}$ and its variability. When compiling the equation of the level of ambient intelligence-AMI (y), we begin at the general notation of the equation $\mathrm{Y}=\mathrm{b} 0+\mathrm{b} 1 \mathrm{x}$.

\section{Results}

We determined the research assumption, the research question and six research hypotheses which we are testing empirically. In the following part of the partial analysis and conclusion construction, in order to construct the answers to the research question, we examed through correlation analysis the dependence between variables, predictors affecting the building of ambient intelligence of a company (AMI level), which generally suggests some possibility of prediction. 
Building ambient intelligence for an enterprise largely depends (Table 4) on the introduction elements of virtualization, which the enterprise integrates in business processes (Kendall's Tau-C = $0.407, p<0.05$; Spearman's $\varrho=0.523, p<0.05$ ) and the extent to which enterprises analyze and assess data (Kendall's Tau-C $=0.392, p<0.05$; Spearman's $\varrho=0.499, p<0.05$ ). The medium degree of strength of the relationship of the achieved level of ambient intelligence of the enterprise can be identified in the management attitude towards integration of innovative pervasive technologies into business processes (Kendall's Tau-C $=0.385, p<0.05$; Spearman's $\varrho=0.483, p<0.05$ ), introducing elements of digitization (Kendall's Tau-C $=0.371, p<0.05$; Spearman's $\varrho=0.470, p<0.05$ ).

Table 4. Correlation between predictors and the level of ambient intelligence of an enterprise.

\begin{tabular}{ccc}
\hline Explanatory Variable & Coefficient & AMI Level \\
\hline \multirow{2}{*}{ Data analysis degree } & Kendall's Tau-C & $0.392^{* *}$ \\
& Spearman's $\varrho$ & $0.499^{* *}$ \\
\hline \multirow{2}{*}{ Data significance } & Kendall's Tau-C & $0.286^{* *}$ \\
& Spearman's $\varrho$ & $0.385^{* *}$ \\
\hline \multirow{2}{*}{ Digitization } & Kendall's Tau-C & $0.371^{* *}$ \\
& Spearman's $\varrho$ & $0.470^{* *}$ \\
\hline \multirow{2}{*}{ Virtualization } & Kendall's Tau-C & $0.407^{* *}$ \\
& Spearman's $\varrho$ & $0.523^{* *}$ \\
\hline \multirow{2}{*}{ Augmented reality } & Kendall's Tau-C & $0.255^{* *}$ \\
& Spearman's $\varrho$ & $0.334^{* *}$ \\
\hline \multirow{2}{*}{ Management attitude to integration of technologies } & Kendall's Tau-C & $0.385^{* *}$ \\
& Spearman's $\varrho$ & $0.483^{* *}$ \\
\hline
\end{tabular}

Note: ${ }^{*} p=0.05,{ }^{* *} p=0.01$. Source: own processing.

We found a small level of correlation in the relationship between the achieved level of ambient intelligence of the enterprise and the importance which the company attaches to the obtained data (Kendall's Tau-C $=0.286, p<0.05$; Spearman's $\varrho=0.385, p<0.05$ ) and introduction of augmented reality elements (Kendall's Tau-C $=0.255, p<0.05$; Spearman's $\varrho=0.334, p<0.05$ ).

We state that constructing ambient intelligence of an enterprise largely depends on the level of virtualization of business processes and the extent to which enterprises analyze and assess data. The level of building ambient intelligence in an enterprise to a medium extent depends on the attitude of the enterprise's management towards innovative pervasive technologies and their integration into business processes, the level of digitization of business processes. There is a small degree of dependence between the level of constructing the enterprise's ambient intelligence and the importance that the enterprise's management attaches to the obtained data and the level of implementation of augmented reality elements into business processes.

Using correlation, we calculated the degree of linear interdependence between the variables. In the following section, we examine the functional and casual relationship between the variables and, using linear regression analysis, we quantify it exactly.

The results of the verification of hypotheses 1-6 (Table 5) showed that the individual predictors have autonomously a statistically significant effect on the achieved level of ambient intelligence. 
Table 5. Evaluation of the research hypotheses.

\begin{tabular}{ccccccc}
\hline Explanatory Variable & B & SE B & $\boldsymbol{\beta}$ & Adjusted $\mathbf{R}^{\mathbf{2}}$ & $\mathbf{F}(\mathbf{1 , 2 0 4 )}$ & $\mathbf{H}_{\mathbf{0}}$ vs. $\mathbf{H}_{\mathbf{1}}$ \\
\hline RH1 Data significance & 0.314 & 0.044 & $0.445^{* *}$ & 0.194 & $50.285^{* *}$ & $\mathrm{H}_{1}$ \\
RH2 Data analysis degree & 0.338 & 0.039 & $0.515^{* *}$ & 0.261 & $75.513^{* *}$ & $\mathrm{H}_{1}$ \\
RH3 Digitization level & 0.437 & 0.047 & $0.543^{* *}$ & 0.291 & $85.193^{* *}$ & $\mathrm{H}_{1}$ \\
RH4 Virtualization & 0.340 & 0.038 & $0.533^{* *}$ & 0.280 & $80.782^{* *}$ & $\mathrm{H}_{1}$ \\
RH5 Augmented reality & 0.246 & 0.046 & $0.349^{* *}$ & 0.118 & $28.373^{* *}$ & $\mathrm{H}_{1}$ \\
RH6 Management attitude & 0.441 & 0.047 & $0.549^{* *}$ & 0.298 & $88.001^{* *}$ & $\mathrm{H}_{1}$ \\
\hline
\end{tabular}

Note: RH—research hypothesis; ${ }^{*} p=0.05,{ }^{* *} p=0.01$. Source: own processing.

By confronting the conducted interviews with experts from business, we claim that these individual activities and attitudes do not operate autonomously in the company, but interact with each other. This was the subject of further research and verification. We assume that the mutual interaction effect of individual predictors to the achieved level of ambient intelligence will tend to disappear.

In order to quantify the variables, which affect the level of the enterprise's ambient intelligence as accurately as possible, we applied multiple linear regression. We inserted all analyzed predictors into the model (Table 6).

Table 6. Linear regression model.

\begin{tabular}{cccc}
\hline Explanatory Variable & B & SE B & B \\
\hline RH1 Data significance & 0.037 & 0.049 & 0.052 \\
RH2 Data analysis degree & 0.129 & 0.046 & $0.196^{* *}$ \\
RH3 Management attitude & 0.170 & 0.065 & $0.212^{* *}$ \\
RH4 Digitization & 0.075 & 0.069 & 0.093 \\
RH5 Virtualization & 0.134 & 0.048 & $0.210^{* *}$ \\
RH6 Augmented reality & 0.060 & 0.044 & 0.085 \\
Adjusted R & \multicolumn{3}{c}{0.416} \\
F (6, 199) & \multicolumn{3}{c}{$25.310^{* *}$} \\
N & \multicolumn{3}{c}{206} \\
\hline
\end{tabular}

Note: RH—research hypothesis; ${ }^{*} p=0.05,{ }^{* *} p=0.01$. Source: own processing.

We state, based on multiple linear regression, that the model is statistically significant $\left(R^{2}=0.416\right.$, $\mathrm{F}(3,199)=25.310, p<0.000)$ and it explains up to $41.60 \%$ of variability. However, the individual predictors in mutual interaction are not statistically significant (data significance, digitization, augmented reality).

We removed these statistically insignificant predictors from the linear regression model and constructed a new model.

The conclusions of the statistical survey showed that the level of achieved ambient intelligence of the enterprise is predicted by the extent to which the company analyzes data that are the basis for decision-making: standardized $\beta=0.222, \mathrm{t}(3,205)=3.304, p=0.001$, the enterprise's management attitude towards integration of innovative pervasive technologies into business processes: standardized $\beta=0.279, \mathrm{t}(3,205)=4.063, p<0.000$ and the virtualization level of business processes, standardized $\beta=0.287, t(3,205)=4.452, p<0.000$. The model explains a large part of variance, $R^{2}=0.411, F(3,205)$ $=48.779, p<0.000$, and it explains up to $41.10 \%$ of variability. From multiple linear regression, the equation can be written:

$$
\begin{aligned}
\text { Level AMI }(\mathrm{y})= & 1.408+0.146 \times \text { Data analysis }\left(\mathrm{x}_{1}\right)+0.224 \times \text { Management } \\
& \text { attitude }\left(\mathrm{x}_{2}\right)+0.183 \times \text { Virtualization }\left(\mathrm{x}_{3}\right)
\end{aligned}
$$

The interpretation can be derived from the previous equation: If the level of analysis of the obtained data is increased by one unit, the level of the achieved level of ambient intelligence will increase by 0.146 points. If the enterprise's management attitude strengthens towards innovative 
pervasive technologies, the level of ambient intelligence will increase by an average of 0.224 points. Increasing the level of business processes virtualization by 1 point will increase the level of ambient intelligence by 0.183 points.

\section{Discussion}

Attention in the field of ambient intelligence is concentrated on innovative pervasive technologies, integration of human factor. In relation to analysis of prediction of the level of ambient intelligence, we confronted approaches of individual authors to ambient intelligence and innovative pervasive technologies. We defined activities related to the integration of innovative pervasive technologies: data analysis, but also attitude to data, digitization, virtualization of business processes, implementation of augmented reality. In the analyzed theoretical background, it is possible to identify a significant influence of the human factor, the enterprise's management attitude towards the integration of innovative pervasive technologies into business processes.

We assumed that the activities resulting from the integration of innovative pervasive technologies into business processes and the enterprise's management attitude towards these technologies has a significant impact on the achieved level of ambient intelligence of the company. Based on the assumption, we determined a research question.

RQ: How do selected activities (data analysis, digitization, virtualization of business processes, implementation of augmented reality and attitude, the relationship of business management to data (significance of data), to innovative pervasive technologies) affect the achieved level of ambient intelligence of the enterprise?

By verifying the research hypotheses, we found that individually researched impact on selected activities and attitude, the relationship of an enterprise's management with data and innovative pervasive technologies, statistically significantly affect the achievement of the level of ambient intelligence of the enterprise; however, in mutual interaction they begin to lose their effect. In mutual interaction the achievement of the level of ambient intelligence of the company is influenced by the extent to which the company analyzes data, virtualization of business processes and the enterprise's management attitude to innovative pervasive technologies.

The level of building a company's ambient intelligence largely depends on the level at which companies analyze and assess data and the level of visualization of business processes. The level of building the enterprise's ambient intelligence to a medium extent depends on the attitude of the company's management towards innovative pervasive technologies and their integration into the business processes, the level of digitization of business processes. There is a small degree of dependence between the level of building the enterprise's ambient intelligence and the significance of data that the enterprise's management attaches to the obtained data and the level of implementation of augmented reality into business processes.

At the same time, we state that if the level of analysis of the obtained data increases by one unit, the the achieved level of ambient intelligence will increase by 0.146 points. If the enterprise's management attitude strengthens towards innovative pervasive technologies, the level of ambient intelligence will increase by an average of 0.224 points. Increasing the level of business processes virtualization by 1 point will increase the level of ambient intelligence by 0.183 points.

For companies with an increasing level of data analysis, the level of virtualization of business processes and strengthening the attitude of management to the integration of innovative technologies, the level of the enterprise's ambient intelligence also increases.

Within the discussion and confrontation of theoretical knowledge, we confirm that the findings are in line with the authors who in the definitions of ambient intelligence point to the need and the role of data analysis [27], emphasize the human factor, attitude, relationship of enterprise's management to innovative pervasive technologies $[5,6,28,42]$ and point to the virtualization of business processes $[18,26,36,37]$. The authors appropriately integrate these concepts into the characteristics 
of ambient intelligence. These factors, even in mutual interaction, influence the constructing of the enterprise's ambient intelligence. The support for the Internet of Things (IoT) and the Industrial Internet of Things (IIoT) is very important. Although the opportunity [14] of Industrial Internet of Things (IIoT) for manufacturing and business processes are widely accepted by a majority of players in many industrial sectors, the number of practically deployed Industrial Internet Systems (IISs) is not growing very fast. One of the reasons is the large-scale requirement, which consequently is met with certain technological challenges.

In the research, we found that the individual activities construct ambient intelligence of the enterprise independently. However, a higher degree of the achieved ambient intelligence can be reached directly by the interaction of the high-data analysis combination of realization, virtualization of business processes and a highly positive attitude of an enterprise's management to innovative pervasive technologies.

The realised research has certain limitations. The questionnaire survey was conducted by a random selection of enterprises in the Slovak Republic. The research sample is limited in its regional scope. The measuring instrument can also be considered as a limitation of the research, due to the fact that the respondents answered the individual questions by self-assessment, while their answers could be influenced by various factors (lack of time, their mood, imminent event when filling the questionnaire). These limitations limit the degree of generalization of the findings and conclusions of the research.

\section{Conclusions}

Scientific and technological progress, the onset of the fourth industrial revolution stimulated the emergence of ambient intelligence. The concept of the next generation of information and communication technologies has created a starting point for the construction of a new paradigm, which is ambient intelligence. Literature shows that it is possible to identify the fact that the authors refuse the exact specified definition of ambient intelligence. The genesis of development in the field of definitions of ambient intelligence is shifting from technological orientation to visionary definitions. In the time of ambient intelligence creation, the authors point to technologies which it was made of. In subsequent periods, they gradually integrate the human, social and economic aspects. The current definitions and views of the authors point to the building of an ecosystem with innovative intelligent pervasive technologies that are able to respond to user requirements and also learn. The authors most often work with the concepts of innovative pervasive technologies, communication, mobility, virtualization and human interaction. These concepts, which the authors work with in their definitions, cannot be understood only on a theoretical level, but also as the basis of the concept of the industrial sector. The theoretical contexts we analyzed represent ontological considerations about ambient intelligence, in some cases suggest a view of the future, and the authors' definitions seem visionary.

We state that ambient intelligence is a new concept and vision. It accumulates several functions related to the integration of innovative pervasive information and communication technologies into the environment in cooperation with the user. Ambient intelligence introduces a multidisciplinary approach focusing on the integration of innovative pervasive technologies that support user activities through specific services of surrounding environment. The services are provided with minimal user intervention. Essentially, the system of ambient intelligence should be aware of a person's presence, perceive the person's needs and be able to adapt to the user's needs. Ambient intelligence brings new knowledge about the environment for software development and implementation, which has large numbers of devices and sensors that need to be integrated, creating a programmable and auto-configurable infrastructure of information systems.

The substance of ambient intelligence consists of innovative pervasive technologies, which are characterised by their ubiquity (pervasiveness), the ability to collect, assess and analyze data. These technologies communicate and interact, unobtrusively respond to the user's requirements and they are capable of learning. Enterprises, in order to build ambient intelligence, perform activities such as 
data analysis, digitization, virtualization of business processes and implement augmented reality into business processes. These activities must be supported by the Internet of Things (IoT) and the building of an Industrial Internet of Things (IIoT).

By quantifying the predictors influencing the level of ambient intelligence, we found that the achieved level of ambient intelligence of the enterprise is predicted by the extent to which the enterprise analyzes data, attitudes, enterprise's management relationship to integrating innovative pervasive technologies into business processes and the level of business process virtualization. We found that these activities even build ambient intelligence on their own, although in interaction with each other their effect on the level of ambient intelligence begins to fade. Therefore, it is necessary to opt for their combination appropriately.

Enterprises will most significantly achieve the level of ambient intelligence through a high degree of data analysis, business process virtualization and a positive attitude of business management towards innovative pervasive technologies. When virtualizing business processes, enterprises need to have digitized individual processes in which innovative pervasive technologies intercommunicate. Furthermore, data analytics plays an important role. It provides relevant data for the response of individual technologies. Without the positive attitude of the enterprise's management towards innovative pervasive technologies, the importance of these activities would be lost and building of the enterprise's ambient intelligence could fall behind.

Through realization of the research, we have identified several new research topics in areas related to ambient intelligence. We would like to focus on some of them in the near future and cooperate with other universities and business partners in research in this area. The central focal point would be confrontation and development over time in this area among enterprises in the Slovak Republic, research realization in other countries, regions, so that the results are comparable. The subject matter is also a study in individual sectors of economy and in the field of ambient intelligence integration in information literacy models. Moreover, we have identified the future direction in the limitation of the research that was carried out, and we would like to minimise its impact in subsequent research.

Author Contributions: Conceptualization, Introduction, Theoretical Background, Materials and Methods, Results, Discussion, Conclusion V.B. and A.R. All authors have read and agreed to the published version of the manuscript.

Funding: This research was funded by Scientific Grant Agency of the Ministry of Education, Science, Research and Sport of the Slovak Republic and the Slovak Academy of Sciences (VEGA) grant number 1/0388/20 and the APC was funded by Scientific Grant Agency of the Ministry of Education, Science, Research and Sport of the Slovak Republic and the Slovak Academy of Sciences (VEGA).

Acknowledgments: The paper was elaborated within VEGA No. 1/0388/20 IT Management in Enterprises in Slovakia: International Standards and Norms Versus Individual Business Processes - proportion 100\%.

Conflicts of Interest: The authors declare no conflict of interest.

\section{References}

1. Information Society Technologies Advisory Group (ISTAG). Ambient Intelligence: From Vision to Reality; ISTAG: Brussels, Belgium, 2003.

2. Information Society Technologies Advisory Group (ISTAG). Orientations for Workprogramme 2000 and Beyond; ISTAG: Brussels, Belgium, 1999.

3. Korzun, D.; Balandina, E.; Kashevnik, A.; Balandin, S.; Viola, F. Ambient intelligence services in iot environments. In Emerging Research and Opportunities; Korzun, D., Balandina, E., Kashevnik, A., Balandin, S., Viola, F., Eds.; IGI Global: Dublin, Ireland, 2019.

4. Gregor, S.; Havner, A.R. Positioning and presenting design science research for maximum impact. MIS Q. 2013, 37, 337-355. [CrossRef]

5. Veronica, I.C.; Mirela, G.; Maria, B.D. Modern approaces in the context of ambient intelligence. Ann. Univ. Oradea Econ. Sci. Ser. 2009, 18, 963-968. Available online: http://steconomice.uoradea.ro/anale/volume/2009/ v4-management-and-marketing/197.pdf (accessed on 8 August 2020). 
6. Aarts, E.; De Ruyter, B. New research perspectives on ambient intelligence. J. Ambient Intell. Smart Environ. 2009, 1, 5-14. [CrossRef]

7. Ducatel, K.; Bogdanowicz, M.; Scapolo, F.; Leijten, J.; Burgelman, J.-C. Scenarios for Ambient Intelligence in 2010 Union Européenne; Technologies de la Société de l'Information; Institut d'Etudes de Prospectives Technologiques; Société de l'Information Conviviale; Union Européenne; Office for Official Publications of the European Communities: Luxembourg, 2001; pp. 3-8.

8. Shadbolt, N. Ambient intelligence. IEEE Trans. Intell. Transp. Syst. 2003, 18, 2-3.

9. Remagnino, P.; Foresti, G.; Ellis, T. Ambient Intelligence; Springer: New York, NY, USA, 2005.

10. Weber, W.; Rabaey, J.; Aarts, E. Ambient Intelligence; Springer: Amsterdam, The Netherlands, 2005.

11. Aarts, E.; Encarnação, J.L. True Visions: The Emergence of Ambient Intelligence; Springer: Berlin/Heidelberg, Germany, 2006.

12. Aarts, E.; Harwig, R.; Schuurmans, M. Ambient Intelligence. The Invisible Future; McGraw-Hill: New York, NY, USA, 2001; pp. 235-250.

13. Cook, D.J.; Augusto, J.C.; Jakkula, V.R. Ambient intelligence: Technologies, applications, and opportunities. Pervasive Mob. Comput. 2009, 5, 277-298. [CrossRef]

14. Gurtov, A.; Liyanage, M.; Korzun, D. Secure communication and data processing challenges in the Industrial Internet. Balt. J. Mod. Comput. 2016, 4, 1058-1073. [CrossRef]

15. Vasilakos, A.; Pedrycz, W. Ambient Intelligence, Wireless Networking, and Ubiquitous Computing; Artech House, Inc.: Norwood, MA, USA, 2006.

16. Phillips Research. Other perspectives on ambient intelligence. In Ambient Intelligence; Springer: Amsterdam, The Netherlands, 2007.

17. Augusto, J.C.; McCullagh, P. Ambient intelligence: Concepts and applications. Comput. Sci. Inf. Syst. 2007, 4, 1-27. [CrossRef]

18. Ramos, C.; Augusto, J.C.; Shapiro, D. Ambient intelligence-the next step for artificial intelligence. IEEE Intell. Syst. 2008, 23, 15-18. [CrossRef]

19. Kleinberger, T.; Becker, M.; Ras, E.; Holzinger, A.; Müller, P. Ambient Intelligence in Assisted Living: Enable elderly people to handle future interfaces. In Universal Access in Human Computer Interaction, Proceedings of the International Conference on Universal Access in Human-Computer Interaction, Las Vegas, NV, USA, 15-20 July 2007; Springer: Berlin/Heidelberg, Germany, 2007; pp. 103-112.

20. van Hoof, J.; Kort, H.S.M.; Rutten, P.G.S.; Duijnstee, M.S.H. Ageing-in-place with the use of ambient intelligence technology: Perspectives of older users. Int. J. Med. Inf. 2011, 80, 310-331. [CrossRef] [PubMed]

21. Bravo, J.; Coronato, A.; Curran, K.; De Pietro, G.; Qiushi, R.; Sarrafzadeh, M. Editorial to the special section on ambient intelligence and assistive technologies for cognitive impaired people. IEEE J. Biomed. Health Inform. 2014, 18, 352. [CrossRef] [PubMed]

22. Kortuem, G.; Kawsar, F.; Sundramoorthy, V.; Fitton, D. Smart objects as building blocks for the internet of things. IEEE Internet Comput. 2010, 14, 44-51. [CrossRef]

23. Wang, J.; Zhu, Q.; Ma, Y. An agent-based hybrid service delivery for coordinating internet of things and 3rd party service providers. J. Netw. Comput. Appl. 2013, 36, 1684-1695. [CrossRef]

24. Perera, C.; Zaslavsky, A.; Christen, P.; Georgakopoulos, D. Context Aware Computing for the Internet of Thing; IEEE: Piscataway, NJ, USA, 2014.

25. Korzun, D. On the Smart Spaces Approach to semantic-driven design of service-oriented information systems. In Database and Informatic Systems, Proceedings of the 12th International Baltic Conference on Databases and Information Systems (DBEIS 2016), Riga, Latvia, 4-6 July 2016; Arnicans, G., Borzovs, J., Arnicane, V., Niedrite, L., Eds.; Springer International Publishing: Berlin/Heidelberg, Germany, 2016; pp. 1-15.

26. Smit, J.; Kreutzer, S.; Moeller, C.; Carlberg, M. Industry 4.0: Study; European Parliament: Brussels, Belgium, 2016.

27. Kaptein, M.C. Computational Personalization. Data Science Methods for Personalized Health; Technical report; University of Tilburg: Tilburg, The Netherlands, 2018.

28. Charitos, D. Precedents for the Design of Locative Media. Future Interaction Design II; Saariluoma, P., Isomäki, H., Eds.; Springer: London, UK, 2008.

29. Streitz, N. Beyond 'smart-only' cities: Redefining the 'smarteverything' paradigm. J. Ambient Intell. Hum. Comput. 2018, 10, 791-812. [CrossRef] 
30. Streitz, N. Reconciling humans and technology: The role of ambient intelligence; Keynote Paper. In Lecture Notes in Computer Science (LNCS), Proceedings of the 2017 European Conference on Ambient Intelligence, Malaga, Spain, 26-28 April, 2017; Braun, A., Wichert, R., Mana, A., Eds.; Springer: Berlin/Heidelberg, Germany, 2017; Volume 10217, pp. 1-16. [CrossRef]

31. Crutzen, C.K. Invisibility and the meaning of ambient intelligence. Int. Rev. Inf. Ethics 2006, 6, 52-62. Available online: http://www.i-r-i-e.net/inhalt/006/006_Crutzen.pdf (accessed on 15 August 2020).

32. Fabian, B.; Hansen, M.; Technische, G.; Bizer, J.; Spiekermann, S.; Günther, O. Taucis-Technologiefolgenabschätzung Ubiquitäres Computing und Informelle Selbstbestimmung; Unabhängiges Landeszentrum für Datenschutz Schleswig-Holstein: Kiel, Germany, 2006; pp. 11-44.

33. Ramos, C. Ambient intelligence-A state of the art from artificial intelligence perspective. In Portuguese Conference on Artificial Intelligence; Springer: Berlin/Heidelberg, Germany, 2007; pp. 285-295. Available online: https://link.springer.com/chapter/10.1007/978-3-540-77002-2_24 (accessed on 11 August 2020).

34. Phillips Research. Ambient intelligence: Changing lives for the better. In Ambient Intelligence; Springer: Amsterdam, The Netherlands, 2007.

35. Bureš, V.; Tučník, P.; Mikulecký, P.; Mls, K.; Blecha, P. Application of ambient intelligence in educational institutions: Visions and architectures. Int. J. Ambient Comput. Intell. (IJACI) 2016, 7, 94-120. [CrossRef]

36. Weiser, M. The computer of the twentyfirst century. Sci. Am. 1991, 265, 66-75. Available online: https: //www.ics.uci.edu/ \{\}corps/phaseii/Weiser-Computer21stCentury-SciAm.pdf (accessed on 10 August 2020). [CrossRef]

37. Xu, G.Y.; Shi, Y.C.; Xie, W.K. Pervasive/ubiquitous computing. Chin. J. Comput. 2003, 9. Available online: http://cjc.ict.ac.cn/quanwenjiansuo/xgy09.pdf (accessed on 10 August 2020).

38. Ark, W.; Selker, T. A look at human interaction with pervasive computers. IBM Syst. J. 1999, 38, 504-507. [CrossRef]

39. Hansmann, U.; Merk, L.; Nicklous, M.S.; Stober, T. Pervasive Computing Handbook; Springer: Berlin/Heidelberg, Germany, 2001.

40. Müller-Veerse, F. Mobile Commerce Report; Durlacher Research Ltd.: London, UK, 1999.

41. Rech, J.; Althoff, K.D. Artificial intelligence and software engineering: Status and future trends. Künstliche Intell. 2004, 18, 5-11. Available online: https://www.semanticscholar.org/paper/Artificial-Intelligenceand-Software-Engineering\%3A-Rech-Althoff/1ddd1c36a1226f0a04565b13b5ec3d3ee552aef5 (accessed on 10 August 2020).

42. Riva, G.; Vatalaro, F.; Davide, F. The evolution of technology, communication and cognition towards the future of human-computer interaction. In Ambient Intelligence; Riva, G., Vatalaro, F., Davide, F., Eds.; IOS Press: Amsterdam, The Netherlands, 2005; Volume 6.

43. Ahola, J. Ambient Intelligence; Final Report; IST Advisory Group: Vaduz, Liechtenstein, 2001.

44. Maeda, E.; Minami, Y. Steps toward Ambient Intelligence; NIT Technical Review: New Delhi, India, $2006 ;$ p. 4. 